\title{
Management of Interdependencies in Defence Capability Portfolio
}

\author{
Ivan L. Garanovich, Garth de Visser, Minh-Tuan Nguyen, Andrew Gill, Anthony Ween, \\ Defence Science and Technology Organisation (DSTO), \\ Department of Defence, Canberra, Australia \\ Email: ivan.garanovich@dsto.defence.gov.au
} Tim Heseltine, Li Jiang, Jamie Watson, Richard Taylor, Duncan Tailby and Hossein Seif Zadeh

\begin{abstract}
The aim of this study is the development of methods and tools for analysis and management of interdependencies in the Defence capability portfolio. Capability development in Defence aims to develop and maintain the most operationally effective and cost-efficient mix of capabilities required to achieve Government's strategic objectives (Defence Capability Development Handbook, 2012). The fiscal and other resource constraints mean that wise choices have to be made regarding capital and resource investments. In a traditional project management, success of an individual project is usually assessed against its own unique set of goals. However, in the large Defence enterprise, multiple projects are underway at the same time, which have many direct and indirect interdependencies. Therefore, effective definition, development, and implementation of the Defence capability projects are practically impossible without taking into account all project interdependencies and portfolio approach to defence capability development is desirable.
\end{abstract}

In this paper, we start by reviewing international best practices in the application of Project Portfolio Management (PPM) in the Defence context, including multi-criteria decision analysis and portfolio optimisation techniques. PPM could provide a better way for achieving an effective and balanced Defence Capability Portfolio. Analogous to Program Management, referring to managing a set of projects, Portfolio Management refers to managing a set of related programs within an organisation. Defence Capability Portfolio includes all of the capability-related projects and programs within the Defence enterprise, including planned and ongoing capability development projects from the various domains including air, maritime and land. Portfolio Management does not represent one particular method; it is rather a general approach within which many alternative methods exist.

Development of a consistent framework for the interdependencies is required as various Defence stakeholders have very different and often conflicting views on the nature and type of project interdependencies. Following the summary of best practices, we present our work on identifying and categorising project interdependencies in the Defence Capability Portfolio. We use the international best practices to identify a set of canonical project interdependencies which are most relevant to Defence capability development. We find that interdependencies between the Defence capability projects fall into one of the four following major categories: benefit interdependency, resource interdependency, operational interdependency and risk interdependency. Collectively, the above categories cover the spectrum of capability, cost and schedule interdependencies in Defence capability development.

We apply network analysis techniques to identify important project clusters and also to visualise project interdependencies. The projects are represented as network nodes and interdependencies are modelled as links. In the last two decades many empirical and analytical methods, techniques and tools have been developed to aid network analysis. These tools have provided numerous measures and algorithms that have proved to be very useful in studying network properties and behaviour, both static and dynamic. We utilise a sample set of techniques to analyse a sample network of projects.

We also present a prototype interactive tool for automated project rescheduling in the Defence Capability Plan (DCP) which takes into account critical interdependencies between project delivery milestones. The DCP rescheduling problem is formulated as an iterative sequence of Mixed Integer Linear Programs (MILP) which is used to determine a feasible schedule that satisfies all budget constraints whilst satisfying the interdependency constraints.

Keywords: Defence Capability Portfolio, Portfolio Management, Project Interdependencies, Network Analysis, Project Scheduling 


\section{DECISION SUPPORT FOR CAPABILITY DEVELOPMENT}

The aim of this study is the development of methods and decision support tools for analysis and management of interdependencies in the Defence capability portfolio. Section 2 introduces the notion of Defence capability. Section 3 reviews application of portfolio management techniques for the capability development. Section 4 identifies various interdependency types which exist in the capability portfolio. Section 5 presents our network analysis of the interdependencies in the capability portfolio, and Section 6 describes our prototype optimisation tool for the capability portfolio rescheduling.

\section{DEFENCE CAPABILITY}

In the context of the Australian Defence Organisation the term "capability" can have a variety of different meanings. Capability Development Group (CDG), which focuses on developing proposals for Major Capital Equipment (MCE) to be used by the Australian Defence Force (ADF), defines capability as "the capacity or ability of the ADF to achieve a particular operational effect". Capability in this context is the combined effect of multiple Fundamental Inputs to Capability (FIC), which are categorised and broadly defined as: Personnel, Organization, Collective Training, Major Systems, Supplies, Facilities, Support, Command and Management (Defence Capability Development Handbook, 2012).

Capability-based Planning (CBP) has become the recognised standard for Defence planning internationally. The key idea is to start with what needs to be done and work back to an affordable force that can achieve the desired outcome (Davis, 2002, De Spiegeleire, 2011, Filinkov and Dortmans, 2012, Moon et al., 2013, Taylor, 2012, Webb et al., 2010). In Australia, the Defence Capability Plan (DCP) provides a ten-year program of MCE projects (Defence Capability Plan 2009, 2009). Entry of projects into the DCP is the foundation for all subsequent capability development work in Defence.

\section{CAPABILITY PORTFOLIO MANAGEMENT}

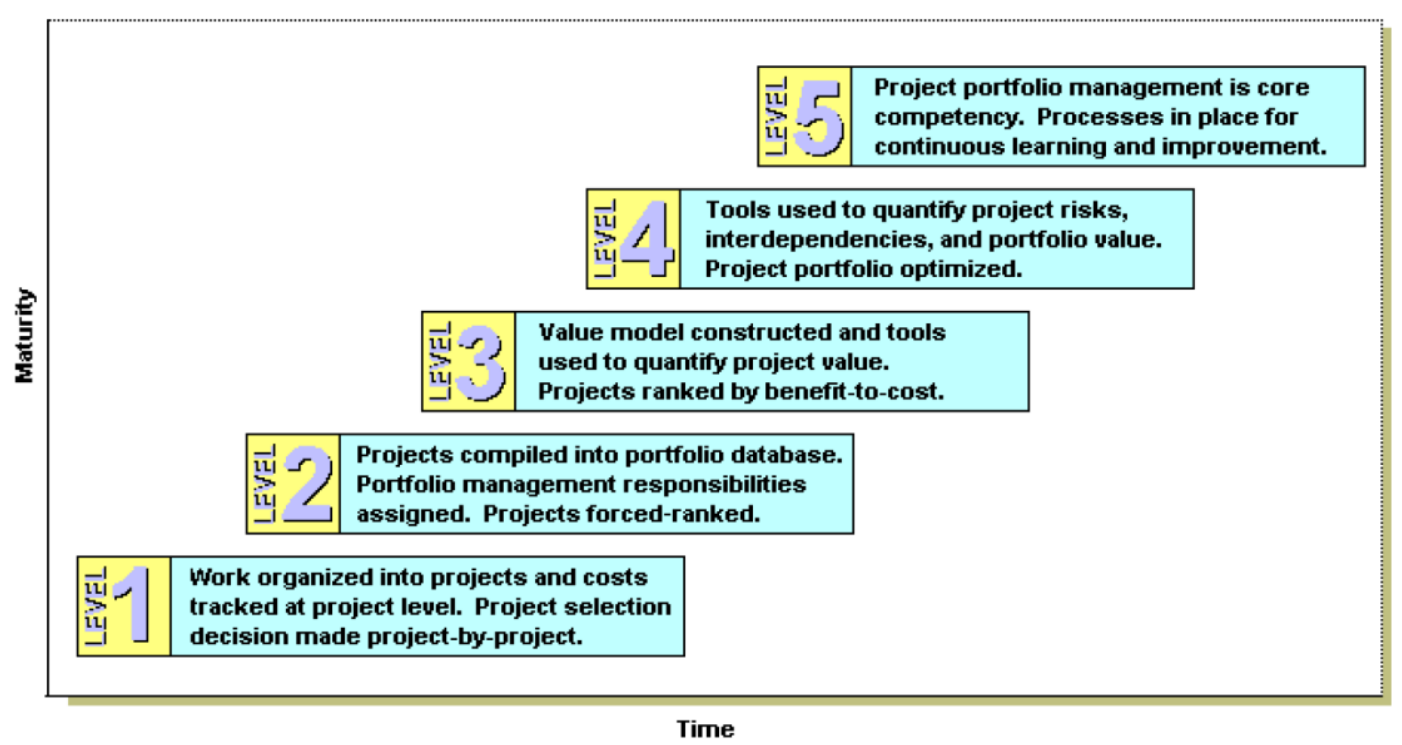

Figure 1. Five levels of Project Portfolio Management maturity (Merkhofer, 2012).

Because there is a large and diverse set of stakeholders in Defence, each with their own interests and a different idea of what military capabilities should be, a multiple objective Project Portfolio Management (PPM) approach to capability development can significantly improve the overall capability operational efficiency and portfolio value for money. While there is no single commonly accepted definition of PPM, the following statement captures the essence of PPM very well: project portfolio management may be defined as a means for assessing the contributions and balance of a collection of projects aimed at achieving a common goal (Landree et al., 2009). This is in contrast to assessing individual projects independently and against their own unique set of goals. PPM techniques have been developed and successfully implemented in various public sector organisations and commercial enterprises for more than half a century (The Best Management Practice website (UK), 2012, Project Management Institute (USA), 2012). In the Defence context, capability portfolio often draws on system, systems of systems, or architecture theories and techniques. 
Many different projects usually contribute to delivering a specific capability, and conversely the same project often contributes to delivering several different capabilities. Therefore, the rationale for CBP is closely related to PPM because capability investment decisions cannot be made one system at a time, but must address how new candidate systems interact among themselves and complement currently fielded systems in order to achieve the maximum overall effectiveness of the resulting "system of systems" architecture.

PPM has attracted considerable interest from Defence organisations internationally. In particular, the U.S. Deputy Secretary of Defence mandated that all U.S. DoD agencies are to use capability portfolio management to optimise capability investments and minimise risk in meeting the U.S. DoD needs across the Defence enterprise (Capability Portfolio Management, 2008). Methods and frameworks for Defence capability portfolio management are being actively developed by leading Defence research organisations including RAND (Chow et al., 2012, Davis and Dreyer, 2009, Davis et al., 2008, Landree et al., 2009), MITRE (Moynihan, 2005, Moynihan et al., 2009), and U.S. Military Academy (Burk and Parnell, 2011, Ewing et al., 2006, Geis II et al., 2011, Parnell and Trainor, 2009). Figure 1 proposes five levels of Project Portfolio Management maturity (Merkhofer, 2012). Each level represents the adoption of increasingly comprehensive and effective subsets of PPM. Our literature review suggests that the current level of PPM maturity in the majority of TTCP and NATO nations is between the Level 1 and Level 2 (awareness of interdependencies). Therefore, a considerable analytical work and organisational change is required to progress to the Level 5 (optimised portfolio).

\section{INTERDEPENDENCIES IN CAPABILITY PORTFOLIO}

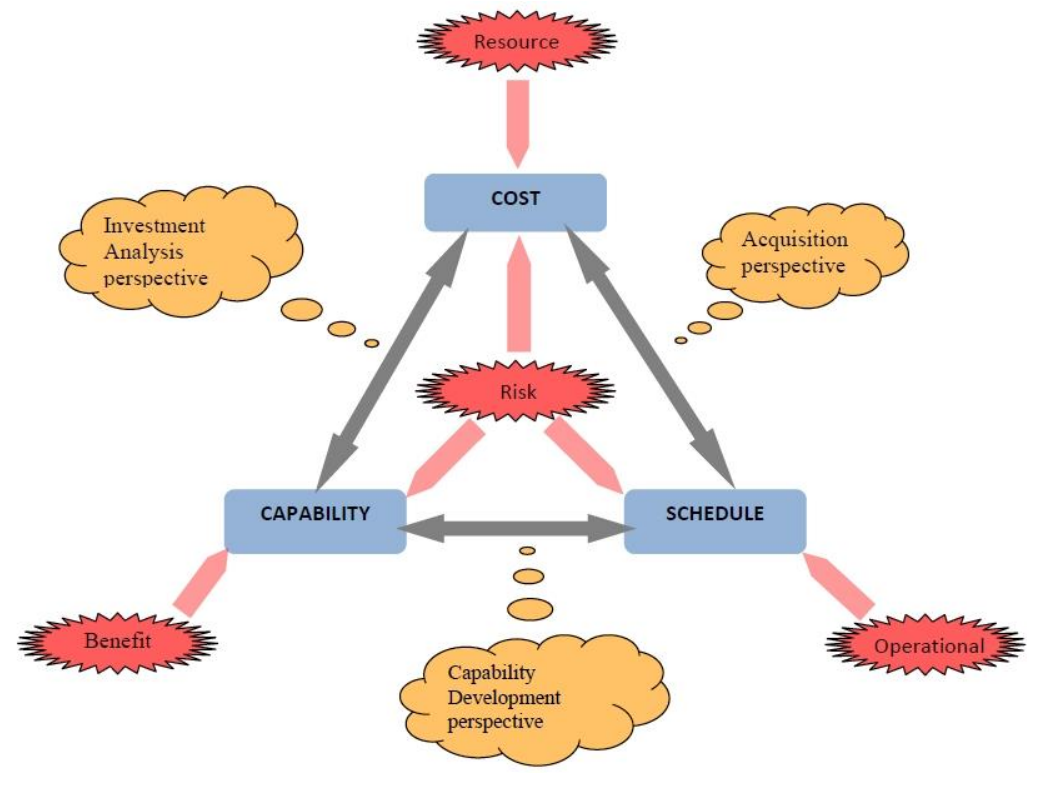

Figure 2. Relationship between interdependency types and Defence Capability Development.

Much like any other project portfolio, Defence projects contribute to the overall Defence capability in ways that are affected by the presence of other projects. For instance, a particular platform or system may be unable to be deployed on its own, but will act as a "force multiplier" to existing force elements. Alternatively, it may be necessary for a particular project to enter service at least by the date that its predecessor is taken out of service, in order to maintain continuity of capability.

The very complex and intricate interdependencies between Defence projects add a level of complexity to the planning and management of the Defence capability portfolio. Alterations cannot be made to one particular area of the portfolio without potentially affecting other areas as well. Managing project interdependencies in the Defence capability portfolio is highly desired if Defence is to be able to generate the effects required by Strategic Guidance in the future.

Despite the plurality among the different typologies, most can be fully or partly mapped to the following set of four interdependency types [see (Aaker and Tyebjee, 1978, Blecic et al., 2008, Dickinson et al., 2001, Fox et al., 1984, Kendrick, 2003, Maizlish and Handler, 2005, Moon et al., 2013, Schmidt, 1993, Verma and Sinha, 2002)] which appear to be most relevant to Defence capability development: 
Benefit interdependency is when the value of several interdependent projects is greater (synergism) or less (antagonism) than the sum of the individual project values - for example, when one project stimulates demand for another, or when one project partially substitutes for another.

Resource interdependency is when the cost of several interdependent projects is different to the sum of the individual project costs - for example, when resources are shared between projects.

Operational interdependency occurs when relationships between the in-service lifetimes of existing or new key assets place constraints on the scheduling parameters of projects for example, operating one asset prior to operating another (prerequisite); or one asset may only operate while another asset operates (concurrent); or one asset must begin operating when another asset stops operating (contiguous), or logical constraints on the selection of projects - for example, where a project belonging to the set can only be chosen if no other project from the set is selected (mutually-exclusive); or where a project belonging to the set can only be selected if all other projects in the set are also selected (contingent).

Risk interdependency arises when the distribution of one project's key parameter(s) is conditional on another project's key parameter(s) or, more generally, when one project has an effect on the "probability of success" of another project - for example, technical risk of one project (e.g. a radar system) may severely impact the timely completion of another project (e.g. an AEWC).

Benefit interdependency is perhaps the most important, albeit perhaps the most difficult to model, interdependency in the Defence capability planning context. The synergy of combined arms (infantry, armour and artillery) has long been a principle of military operations, and the inclusion of redundancy in military systems can be viewed either as antagonistic through a portfolio perspective, or as an organisational resilience mechanism through a strategic management perspective.

Risk interdependencies exist due to the inherent uncertainty involved in Defence planning, for example when the successful second-pass approval of a project is highly influenced by the success or failure of one or more other project(s). The key parameters defining a project, i.e., capability, cost and schedule, should therefore be viewed as random, and not deterministic, variables.

Collectively, the above categories cover the spectrum of capability, cost and schedule interdependencies in Defence capability development. Figure 2 illustrates the four canonical interdependency categories and their relationship with the key planning parameters associated with Defence capability development and the associated stakeholder groups.

\section{NETWORK ANALYSIS OF INTERDEPENDENCIES}

A new approach in analysis the complex relationship of human or machine interactions has been gaining momentum in recent times. Known as network analysis (Wasserman and Faust, 1994), this approach might provide additional insight into the complicated nature of project interrelationships, where the projects are treated as network nodes and interdependencies are modelled as links between the network nodes (Ween et al., 2011). In the last two decades many empirical and analytical methods, techniques, and tools have been developed to aid network analysis (Borgatti et al., 2002, Carley, 2006b, Carley, 2011, Csardi and Nepusz, 2006). These tools have provided numerous measures and algorithms (Carley, 2011) that have proved to be very useful in studying network properties and behaviour, both static and dynamic (Barabasi, 2005, Dorogovtsev et al., 2000, Killen et al., 2010, NRC, 2005, Shirley and Rushton, 2005, Strogatz, 2001). Various properties and the structural features of a dependency network can be inferred and systematically analysed using visualisation, statistical analysis, machine learning, simulation, experimentation and other mechanisms provided by the network analysis tools (Jiang and Zadeh, 2012).

Analysing a collection of projects by using network measures has widely been used in the social network analysis community. The use of measures such as Bonacich Power Centrality (Bonacich, 1987), the centrality in degree, centrality out degree, centrality betweenness, clustering coefficient, centrality closeness (Wasserman and Faust, 1995) has been proposed. We employed these measures to identify which nodes (representing projects) have the maximum numbers of outgoing links and incoming links (representing links to its children and parent projects respectively), and which nodes have more impact on the network than others. Figure 3 (a) shows an example of a project dependency network. The data is fictional and for illustration purpose only due to the confidentiality of the original data. Bonacich Power Centrality is used to measure the extent a node with high number of connections is connected to the others. It accurately shows the impact of one node on the entire network. 
Selective grouping of similar projects can also provide an insight into how the projects interact with each other individually and as a group. Many grouping algorithms have been developed in network research, including for example, Newman (Newman, 2004) and CONCOR (Breiger et al., 1975) algorithms. These clustering analysis allow us to look at the classification of the project dependency network (or sub-networks) from different perspectives. Each cluster (sub-network) contains a set of projects that has its own unique characteristics. The results of these clustering analyses allow us to look at the Defence force structures from different perspectives.

At any time, a project may be postponed or cancelled due to the monetary or other resource constraints. Change impact analysis can provide an insight into how such a change might impact the entire network. We used Immediate Change impact analysis to analyse the impact of removing a node from the network on the network structure and the node level measures. Figure 3 (b) shows the project dependency network after removing a single node with high value of Bonacich Power Centrality. As can be seen, removing such a node does significantly change the network structure. Furthermore, this change also impacts other network measurements at node level (some nodes measures changed by more than $40 \%$ ). This impact analysis provides a valuable insight (sensitivity analysis) for decision-making in Defence capability planning. Interested reader is referred to (Jiang and Zadeh, 2012) for more detail.

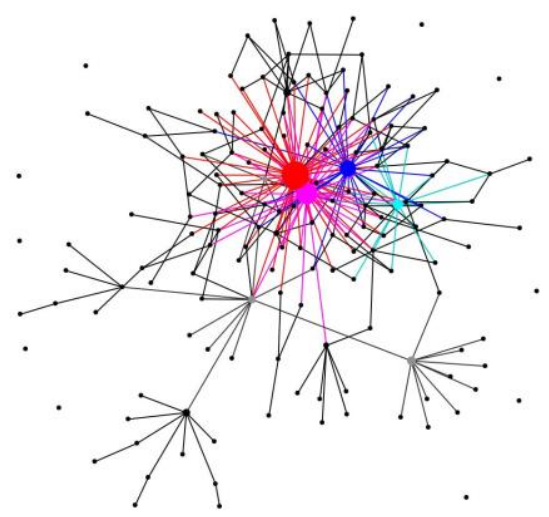

(a)

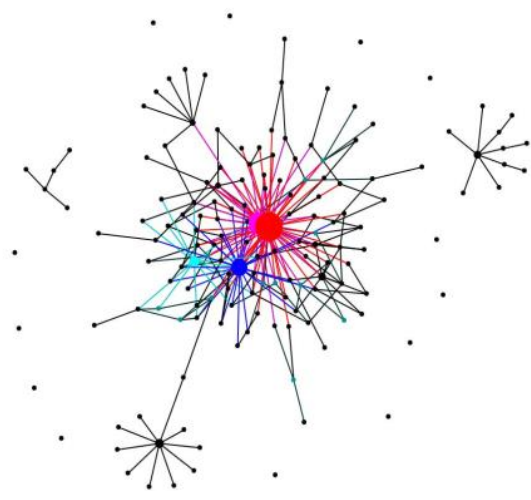

(b)

Figure 3. The change of the network structure before and after removing a single node with high value of Bonacich Power Centrality. Size and colour of nodes show their Bonacich Power Centrality.

\section{PROJECT RESCHEDULING}

A typical Defence Capability Plan (DCP) rescheduling problem starts with an existing schedule of DCP projects - defined by specifying the Year of Decision (YOD) for each project; an estimated length of time to be subsequently spent in the Defence Materiel Organisation (DMO) before realising the operational capability; along with a multi-year estimated cost profile that the project will incur. This schedule will typically satisfy a number of interdependency constraints - either 'replacement project' constraints (a DCP project realising a capability that is to replace an existing Key Defence Asset (KDA)) or 'requirement' constraints (a decision on one project must be taken before a decision on another project can be taken). While there are a number of reasons why the DCP may need rescheduling, often it is the case that some budget cut has occurred so that the total cost of all projects exceeds the (new) given budget in at least one of the planning years. The problem then is to determine a new schedule that satisfies the new budget constraints whilst not breaking any of the interdependency constraints. Ideally, one would not want to either slip many projects or slip projects by many years.

The DCP rescheduling problem can be expressed as an iterative sequence of Mixed Integer Linear Programs (MILP's), where each MILP seeks a one-year slippage solution that minimizes violations of the budget constraints and the number of slipped projects while strictly satisfying the interdependency constraints. The iterations stop when either no feasible solution to the MILP exists, or when only the trivial (zero) MILP solution is returned. In the latter case, the DCP rescheduling problem has a multi-year slippage solution that satisfies all budget approval and interdependency constraints. In the former case, a multi-year slippage solution which minimizes the violation of the budget constraints doesn't exist.

This mathematical formulation was implemented using the GNU Linear Programming Kit (GLPK) solver (see http://www.gnu.org/software/glpk/) and run on a Duo Core HP laptop with 2GB of RAM. A sample of 
actual Defence planning data was used to construct a realistically sized and scoped problem specification, but it should be noted that this doesn't correspond to any past or anticipated future rescheduling activity. The classification of the input data precludes any specific discussion of results, but importantly this proof-ofconcept model did confirm the efficacy of such an approach. The problem contained around 300 binary variables; around 10 real variables; around 170 interdependency constraints; and around a dozen budgetary constraints. The GLPK solver returned an optimal solution in around 3 seconds per iteration.

\section{DISCUSSION AND CONCLUSIONS}

Although defence organisations are aware of interdependency issues, and the impacts interdependencies can have on projects (e.g. cost blowouts, schedule delays and performance shortfalls), their inadequate treatment appears to remain a critical limitation on effective Portfolio Management practices in defence. Systematic and up-to-date interdependency data present the main requirement to the successful implementation of PPM in defence. This study has identified interdependencies most relevant for defence capability development. The suggested interdependency framework can be used as a vehicle to assist in collecting knowledge of subject matter experts and generating the required interdependency data. We have applied network analysis techniques to analyse and visualise interdependencies between capability projects and demonstrated its usefulness in identifying functional project clustering. A prototype interactive automatic rescheduling tool has been developed to address project milestone scheduling issues in the Defence Capability Plan.

\section{ACKNOWLEDGMENTS}

The authors thank Gary Bulluss, Nitin Thakur, Donald Lowe, Paul Malcolm, Sharon Boswell, Peter Dortmans, Tim McKay and Paul Whitbread for providing insightful comments which helped in the framing of this work.

\section{REFERENCES}

Aaker, D. and Tyebjee, T. (1978) Model for the selection of interdependent R\&D projects. IEEE Transactions on Engineering Management 25 (2) pp. 30-36

Barabasi, A.-L. (2005) The origin of bursts and heavy tails in human dynamics. Nature 435 (7039) 207-211

The Best Management Practice website (UK). (2012) [Accessed 2012 September]; Available from: http://www.best-management-practice.com/.

Blecic, I., Cecchini, A. and Pusceddu, C. (2008) Constructing strategies in strategic planning: a decision support evaluation model. Operational Research 8 (2) 2008/08/01 153-166

Bonacich, P. (1987) Power and centrality: A family of measures. American journal of sociology 1170-1182

Borgatti, S. P., Everett, M. G. and Freeman, L. C. (2002) Ucinet for Windows: Software for social network analysis, Harvard, MA: Analytic Technologies.

Breiger, R., Boorman, S. and Arabie, P. (1975) An Algorithm for Clustering Relational Data with Applications to Social Network Analysis and Comparison with Multidimensional Scaling. Journal of Mathematical Psychology 12 328-383

Burk, R. C. and Parnell, G. S. (2011) Portfolio Decision Analysis: Lessons from Military Applications. In: Salo, A., Keisler, J.Morton, A. (eds.). Vol. 162. Springer New York 333-357

Capability Portfolio Management. (2008) DoD Directive \#7045.20, U.S. DoD, Deputy Secretary of Defense Carley, K. (2006b) Meeting Proceedings RTO-MP-IST-063, Neuilly-sur-Seine, France, RTO

Carley, K. *ORA. (2011) [Accessed $20115 \mathrm{March}$ ]; Web page describing the *ORA capability]. Available from: http://www.casos.cs.cmu.edu/projects/ora/.

Chow, B. G., et al. (2012) Toward Affordable Systems III: Portfolio Management for Army Engineering and Manufacturing Development Programs. MG-1187, RAND Corporation

Csardi, G. and Nepusz, T. (2006) The igraph software package for complex network research. InterJournal, Complex Systems 169538

Davis, P. K. (2002) Analytic Architecture for Capabilities-Based Planning, Mission-System Analysis, and Transformation. MR-1513-OSD, RAND Corporation

Davis, P. K. and Dreyer, P. (2009) RAND's Portfolio Analysis Tool (PAT). TR-756, RAND Corporation

Davis, P. K., Shaver, R. D. and Beck, J. (2008) Portfolio-Analysis Methods for Assessing Capability Options. MG-662, RAND Corporation

De Spiegeleire, S. (2011) Ten Trends in Capability Planning for Defence and Security. The RUSI Journal 156 (5) 2011/10/01 20-28

Defence Capability Development Handbook (2012), Department of Defence

Defence Capability Plan 2009 (2009), Department of Defence 
Dickinson, M. W., Thornton, A. C. and Graves, S. (2001) Technology portfolio management: optimizing interdependent projects over multiple time periods. Engineering Management, IEEE Transactions on 48 (4) 518-527

Dorogovtsev, S. N., Mendes, J. F. F. and A. N. Samukhin, A. N. (2000) Structure of Growing Networks with Preferential Linking. Physical Review Letters 85 4633-4636

Ewing, P. L., Jr., Tarantino, W. and Parnell, G. S. (2006) Use of Decision Analysis in the Army Base Realignment and Closure (BRAC) 2005 Military Value Analysis. Decision Analysis 3 (1) 33-49

Filinkov, A. and Dortmans, P. J. (2012) An enterprise portfolio approach for understanding Defence. (submitted 2012)

Fox, G., Baker, N. and Bryant, J. (1984) Economic models for R and D project selection in the presence of project interactions. Management Science 30 (7) 890-902

Geis II, J. P., et al. (2011) Blue Horizons Study Assesses Future Capabilities and Technologies for the United States Air Force. Interfaces June 20, 2011

Jiang, L. and Zadeh, S. H. (2012) Towards the Use of Network Analysis Method In Analysing Node Properties In A System Model In: Model-Based Systems Engineering Symposium, Edingurgh, South Australia. Australia

Kendrick, T. (2003) Identifying and Managing Project Risk. American Management Association

Killen, C., Krumbeck, B. and Kjaer, C. (2010) 2010 Australian Institute of Project Management Conference (AIPM), Australian Institute of Project Management

Landree, E., et al. (2009) A Delicate Balance: Portfolio Analysis and Management for Intelligence Information Dissemination Programs. MG-939, RAND Corporation

Maizlish, B. and Handler, R. (2005) IT Portfolio Management Step by Step. New Jersey, John Wiley and Sons, Incorporated

Merkhofer, L. Choosing the Wrong Portfolio of Projects: 5 Reasons Organizations Choose the Wrong Projects (and What to Do About It). (2012) [Accessed 201227 September]; Available from: http://www.prioritysystem.com/.

Moon, T., Whitbread, P. and Dortmans, P. J. (2013) Networked Enterprise Portfolio Analysis for Defence. Defense and Security Analysis 29 (1) 1-9

Moynihan, R. A. (2005) Investment Analysis using the Portfolio Analysis Machine (PALMA) Tool. MITRE Case Number: 05-0848, MITRE Corporation

Moynihan, R. A., et al. (2009) Enterprise scale portfolio analysis at the national oceanic and atmospheric administration (NOAA). Systems Engineering 12 (2) 155-168

Newman, M. E. (2004) Fast algorithm for detecting community structure in networks. Physical review E 69 (6) 066133

NRC, N. R. C. (2005) Network Science. Washington, Board on Army Science and Technology (BAST), National Academies Press

Parnell, G. S. and Trainor, T. E. (2009) Using the Swing Weight Matrix to Weight Multiple Objectives. In: International Council on Systems Engineering (INCOSE) Symposium, Singapore

Project Management Institute (USA). (2012) [Accessed 2012 September]; Available from: http://www.pmi.org.

Schmidt, R. (1993) A Model for R\&D Project Selection with Combined Benegit, Outcome and Resource Interaction. IEEE Transactions on Engineering Management 40 (4) pp. 403-410

Shirley, M. D. F. and Rushton, S. P. (2005) The impacts of network topology on disease spread. Ecological Complexity 2 (3) 287-299

Strogatz, S. H. (2001) Exploring complex networks. Nature 410 March 8 268-276

Taylor, B. (2012) TTCP JSA TP3 Analysis Support to Strategic Planning. The Technical Cooperation Program (submitted 2012)

Verma, D. and Sinha, K. (2002) Toward a theory of project interdependencies in high tech R\&D environments. Journal of Operations Management 20 pp. 451-468

Wasserman, S. and Faust, K. (1994) Social Network Analysis: Methods and Applications. Cambridge, University of Cambridge Press

Wasserman, S. and Faust, K. (1995) Social Network Analysis: Methods and Applications. Cambridge, University of Cambridge Press

Webb, N. J., Richter, A. and Bonsper, D. (2010) Linking Defense Planning and Resource Decisions: A Return to Systems Thinking. Defense \& Security Analysis 26 (4) 2010/12/01 387-400

Ween, A., Bangura, M. and Rigter, J. (2011) Capability Interdependencies for SEA1180. Joint Operations Division, DSTO 